\title{
Abundância e aspectos reprodutivos de Loricariichthys platymetopon (Siluriformes, Loricariidae) em quatro trechos da represa Capivara, médio rio Paranapanema
}

\author{
Karen M. I. Marcucci ${ }^{1}$, Mário L. Orsi² \& Oscar A. Shibatta ${ }^{2}$ \\ 1. Programa de Pós-Graduação em Ciências Biológicas, Centro de Ciências Biológicas, Universidade Estadual de Londrina (UEL), 86051- \\ 990 Londrina, PR, Brasil. Bolsista CAPES. (ka_marcucci@hotmail.com) \\ 2. Departamento de Biologia Animal e Vegetal, Centro de Ciências Biológicas, UEL. (shibatta@uel.br)
}

\begin{abstract}
Abundance and reproductive aspects of Loricariichthys platymetopon (Siluriformes, Loricariidae) in four sections of the Capivara reservoir, river Paranapanema. The armored catfish Loricariichthys platymetopon was recently caught by the first time in the middle region of river Paranapanema. It has quickly become one of the most abundant species. This study evaluated reproductive aspects of 1,044 specimens collected in the Capivara reservoir. Abundance, sex ratio, RGS, IAR and oocyte diameter were evaluated. Sites far away from the dam showed higher abundances than the one next to it. Breeding occurred when temperature was higher, with moderate intensity. Mean absolute fecundity and mean relative fecundity were $663.95 \pm 141.99$ oocytes and $4.9 \pm 1.24$ oocytes.gr ${ }^{-1}$ respectively. Spawning occurred in batches. Mean diameter of mature oocytes was $3.67 \mathrm{~mm}$.
\end{abstract}

KEYWORDS. Neotropical, Upper Rio Paraná, armored catfish, reproduction, fecundity.

RESUMO. O cascudo Loricariichthys platymetopon foi capturado pela primeira vez recentemente na região média do rio Paranapanema, tornando-se uma espécie abundante desde então. Aspectos reprodutivos dessa espécie foram analisados neste estudo, com base numa amostra de 1.044 exemplares provenientes do reservatório de Capivara. Foram avaliados a abundância, proporção sexual, RGS, IAR e o diâmetro dos ovócitos. Locais distantes da barragem apresentaram as maiores abundâncias, as fêmeas atingiram maiores tamanhos que os machos e a proporção sexual variou entre os trechos de coleta. A reprodução ocorreu principalmente nos meses quentes, com intensidade moderada; as médias da fecundidade absoluta e da relativa foram de 663,95 $\pm 141,99$ ovócitos e 4,9 $\pm 1,24$ ovócitos/g, respectivamente. A desova ocorreu de modo parcelado e o diâmetro máximo médio do ovócito maduro foi de $3,67 \mathrm{~mm}$. Os dados foram relacionados com o sucesso da espécie na ocupação da região.

PALAVRAS-CHAVE. Neotrópico, Alto rio Paraná, cascudo, reprodução, fecundidade.

Loricariichthys platymetopon Isbrücker \& Nijssen, 1979, popularmente conhecido como acari, cascudo-viola ou cascudo-chinelo, ocorre em rios da bacia do Prata. No alto rio Paraná, não foi capturado em levantamentos de ictiofauna realizados antes da formação do reservatório de Itaipu (Reis \& Pereira, 2000), onde se tornou um dos peixes mais abundantes a partir de então.

Estudos realizados até o final da década de 1990 não registraram sua presença no rio Tibagi (BENNEMANN et al., 1995; 2000) e nem no rio Paranapanema, em levantamentos realizados nos reservatórios de Capivara, Salto Grande (Dias \& Garavello, 1998) e Jurumirim (CARVALHO \& Silva, 1999).

Recentes estudos sobre sua biologia foram realizados no rio Paraná (Dei Tos et al., 1997) e na bacia do rio Uruguai (QUEROL et al., 2002), e indicam que habita principalmente ambientes lênticos e semi-lóticos, se reproduz nos meses quentes e que os machos carregam os ovos até o momento da eclosão. Na planície de inundação do alto rio Pananá, a comparação de dados obtidos em períodos com diferentes pluviosidades mostrou que o número de exemplares capturados, o tamanho de primeira maturação e o período reprodutivo são maiores quando a cheia é mais pronunciada (DeI Tos et al., 1997).

O objetivo deste estudo foi analisar a abundância e aspectos da reprodução de L. platymetopon em quatro trechos de uma represa, através da análise da frequiência de captura, da proporção sexual, do período reprodutivo, do tipo de desova, do índice de atividade reprodutiva e da fecundidade da espécie.

\section{MATERIAL E MÉTODOS}

A área de estudo compreendeu o reservatório da usina hidroelétrica (UHE) Escola de Engenharia Mackenzie (também conhecido como represa Capivara) situado no trecho médio do rio Paranapanema, entre as UHEs Salto Grande e Canoas I, e formado em 1975. Comparativamente às outras hidroelétricas desse rio, apresenta a maior área de drenagem $\left(84.500 \mathrm{~km}^{2}\right) \mathrm{e}$ potência instalada (640 MW), e sua drenagem é maior no lado esquerdo (estado do Paraná), onde recebe seus dois grandes afluentes, os rios Tibagi e das Cinzas (Duke ENERGY, 2003). Suas margens são ocupadas por pastos e áreas agrícolas, e os poucos fragmentos florestais ocorrem próximo à foz do rio Tibagi. Para este estudo, quatro trechos foram amostrados ao longo do reservatório, trimestralmente, de abril de 2001 a março de 2003. A transparência foi estabelecida com disco de Secchi, e seu valor informa a média das medições realizadas em cada coleta. A profundidade foi estabelecida por um profundímetro com sonar (Aquatic Ecosystems, Inc), e seu valor representa a média das medições realizadas no canal do rio em cada coleta. A localização e as principais características de cada local são descritas a seguir (fig. 1; tab. I). 
Tabela I. Localização e descrição dos trechos amostrados na represa Capivara e no rio Tibagi. (Vide observações em Material e Métodos).

\begin{tabular}{|c|c|c|}
\hline Trecho & Coordenadas & Principais características \\
\hline I & $\begin{array}{l}50^{\circ} 31 ’ 37^{\prime \prime} \mathrm{W} \\
22^{\circ} 56,16 ” \mathrm{~S}\end{array}$ & $\begin{array}{l}\text { Lótico, raso }(8,9 \pm 3,9 \mathrm{~m}) \text {, transparente }(1,70 \pm 0,70 \mathrm{~m}) \text {, com lagoas } \\
\text { marginais. Recebe o rio das Cinzas e é o mais distante da barragem }\end{array}$ \\
\hline II & $\begin{array}{l}50^{\circ} 50 ’ 34 ” \mathrm{~W} \\
22^{\circ} 46^{\prime} 14^{\prime \prime} \mathrm{S}\end{array}$ & $\begin{array}{l}\text { Lêntico, raso }(6,3 \pm 2,7 \mathrm{~m}) \text {, baixa transparência }(0,70 \pm 0,35 \mathrm{~m}) \\
\text { e afluentes ausentes }\end{array}$ \\
\hline III & $\begin{array}{l}50^{\circ} 57 ' 13 " \mathrm{~W} \\
23^{\circ} 01 ' 16^{\prime \prime} \mathrm{S}\end{array}$ & $\begin{array}{l}\text { Semi-lótico, com profundidade média }(25,9 \pm 3,1 \mathrm{~m}) \text {, } \\
\text { baixa transparência }(0,72 \pm 0,33 \mathrm{~m}) \text { e localizado no rio Tibagi }\end{array}$ \\
\hline IV & $\begin{array}{l}51^{\circ} 19^{\prime} 55^{\prime \prime} \mathrm{W} \\
22^{\circ} 40^{\prime} 44^{\prime \prime} \mathrm{S}\end{array}$ & $\begin{array}{l}\text { Lêntico, profundo }(68,5 \pm 3,5 \mathrm{~m}) \text {, alta transparência }(2,8 \pm 1,01 \mathrm{~m}) \text {, } \\
\text { recebe afluência do rio Vermelho e fica próximo à barragem }\end{array}$ \\
\hline
\end{tabular}

As amostras foram coletadas com redes de espera de diferentes malhas (de 1,3 a $10 \mathrm{~cm}$ entre nós opostos), posicionadas principalmente nas margens, cobrindo, em média, $1.824 \mathrm{~m}^{2}$ de área em cada um dos trechos. As redes foram posicionadas da superfície até próximo ao fundo da área amostrada, e, no trecho mais profundo (IV), foram colocadas até a profundidade de $23 \mathrm{~m}$. O esforço de captura foi padronizado em períodos de 24 horas, com duas revisões de redes e uso de peneiras e redes de arrasto $\left(85 \mathrm{~m}^{2}\right)$ durante duas horas. Os peixes obtidos foram fixados em campo e levados ao laboratório do Museu de Zoologia da Universidade Estadual de Londrina (MZUEL) para identificação das espécies coletadas, realização da biometria, identificação do sexo e determinação do estádio de maturação gonadal. Com base em análise macroscópica, as gônadas foram classificadas em quatro estádios: imaturo (I), início de maturação (II), maduro e parcialmente esgotado (III) e esgotado e repouso (IV), adaptado de DeI Tos et al. (1997), onde as fases do estádio correspondente ao IV foram tratadas de forma separada.

Todas as espécies de peixes coletadas foram identificadas conforme apresentado por SHIBATTA et al. (2002) e depositadas na coleção de peixes do MZUEL, sendo que as da espécie L. platymetopon estão tombadas com o número 1877. Em relação a $L$. platymetopon, a abundância foi avaliada pelo número de exemplares capturados em cada trecho. A captura por unidade de esforço em número (CPUEn) foi calculada pela razão entre a abundância e a área de redes de espera e expressa em número de indivíduos por $100 \mathrm{~m}^{2}$ de rede em 24 horas.

A proporção sexual, o comprimento médio de primeira maturação, a relação gonadossomática (RGS) e o tipo de desova e a fecundidade foram determinados conforme VAzZoLER (1996). A proporção sexual em cada trecho foi testada com o $\chi^{2}$. A pluviosidade média do período da coleta, obtida do centro de operações da Duke Energy International Geração Paranapanema, foi relacionada com a RGS através de correlação de Pearson.

$\mathrm{O}$ índice de atividade reprodutiva (IAR) (AgOstinHO et al., 1993), relaciona a RGS dos indivíduos maduros com o número de indivíduos da amostra e classifica a atividade reprodutiva em incipiente (IAR $\leq 5$ ), moderada $(5<\mathrm{IAR} \leq 10)$, intensa $(10<\mathrm{IAR} \leq 20)$ e muito intensa $(\mathrm{IAR}<20)$.

O tipo de desova, a fecundidade absoluta e a relativa

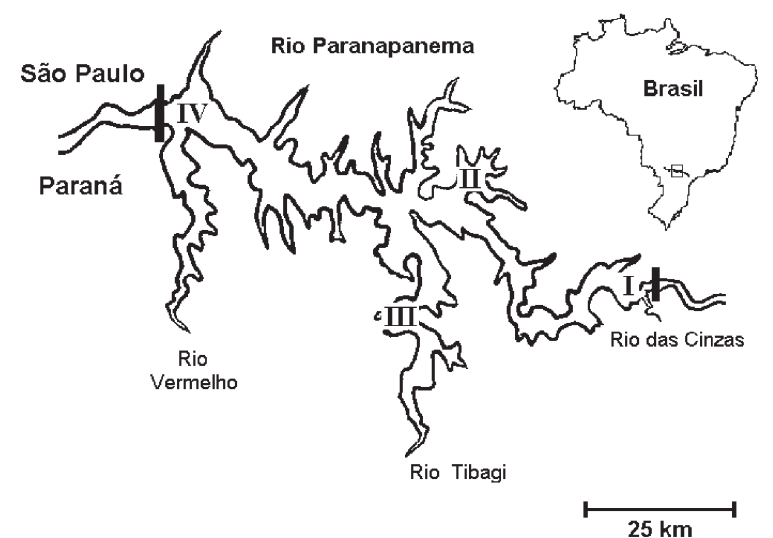

Fig. 1. Localização dos trechos amostrados na represa Capivara e no rio Tibagi.

foram avaliados com base em uma amostra de 15 gônadas de indivíduos fêmeas maduros (comprimento padrão entre 22 e $29 \mathrm{~cm}$ e valores de RGS acima de 7), sendo três fêmeas do trecho IV e quatro de cada um dos demais. O diâmetro dos ovócitos foi medido com um estereomicroscópio equipado com ocular micrométrica e sua distribuição de freqüência foi usada para estimar o tipo de desova. O diâmetro médio de ovócito maduro foi estimado a partir da média aritmética do tamanho de todos os ovócitos maduros. A fecundidade absoluta foi estimada a partir do número total de ovócitos maduros, e a fecundidade relativa, pela razão entre o número de ovócitos maduros e o peso total.

\section{RESULTADOS}

$\mathrm{Na}$ represa Capivara, foram capturados 8.461 exemplares de 80 espécies de peixes durante as 32 coletas realizadas no período de estudo. O número de espécies foi maior no trecho I (59 espécies) e no trecho III (43) que nos trechos IV (31) e II (24), respectivamente. A espécie L. platymetopon compôs $12,3 \%$ dos exemplares obtidos. Foram obtidos 1.044 exemplares e a maior abundância foi apresentada pelo trecho II (541 indivíduos, ou 51\% da amostra); em seguida, por ordem de abundância, vieram os trechos III, I e IV (respectivamente, 23\%, 21\% e 2\% da amostra). Períodos de grande captura se alternaram com amostragens escassas, não sendo observado um padrão definido ao longo das amostragens (tab. II).

Indivíduos adultos constituíram a maior parte da 
Tabela II. Número de indivíduos, abundância relativa (\%), captura por unidade de esforço (CPUEn) de Loricariichthys platymetopon em trechos influenciados pela represa Capivara, entre abril de 2001 e março de 2003.

\begin{tabular}{lcccccc}
\hline Coleta & & \multicolumn{3}{c}{ Trecho } & Total \\
\hline Ano & Mês & I & II & III & IV & \\
\hline 2001 & abril & 7 & 1 & 5 & 8 & 21 \\
& agosto & 24 & 165 & 26 & 1 & 216 \\
& novembro & 40 & 30 & 45 & 7 & 122 \\
2002 & fevereiro & 24 & 32 & 72 & 2 & 130 \\
& junho & 28 & 70 & 0 & 3 & 101 \\
& setembro & 64 & 43 & 50 & 1 & 158 \\
2003 & dezembro & 6 & 184 & 43 & 4 & 237 \\
\hline Total de indivíduos & 226 & 541 & 248 & 29 & 1044 \\
\hline Abundância relativa $(\%)$ & 21,64 & 51,81 & 23,75 & 2,7 & 100 \\
\hline CPUEn & & 12,39 & 29,66 & 13,6 & 1,59 & \\
\hline
\end{tabular}

amostra e os poucos exemplares de pequeno porte foram capturados por peneiras e redes de arrasto. Peixes jovens foram encontrados nos trechos I, II e III; ovos carregados por machos foram obtidos no trecho III. O comprimento padrão do menor indivíduo em estádio avançado de maturação foi 13,4 e $13,5 \mathrm{~cm}$, para fêmeas e machos, respectivamente. As fêmeas foram mais capturadas do que os machos em todos os trechos, mas essa diferença foi significativa apenas nos trechos I e IV (tab. III).

A distribuição da frequiência de machos e fêmeas por classes de comprimento padrão foi equivalente até o tamanho de $20 \mathrm{~cm}$, uma vez que a freqüência dos machos nas classes de $14 \mathrm{~cm}$ até o tamanho de $20 \mathrm{~cm}$, embora maior que a das fêmeas, não foi significativa. Acima deste tamanho, as fêmeas foram mais abundantes $\left(\chi^{2}\right.$ significativo, $p<0,05$ ) (fig. 2).

A variação temporal dos valores de RGS das fêmeas mostrou que a reprodução ocorre de modo mais intenso entre novembro e fevereiro, acompanhando a variação
Tabela III. Número absoluto de imaturos (estádio I), machos e fêmeas de Loricariichthys platymetopon em trechos influenciados pela represa Capivara. O teste $\chi^{2}$ foi aplicado somente para a proporção de machos e fêmeas. * Significativo para $\mathrm{p}<0,05$.

\begin{tabular}{ccccc}
\hline Trecho & Imaturos & Machos & Fêmeas & $\mathrm{p}\left(\chi^{2}\right)$ \\
\hline I & 9 & 76 & 140 & $0,003^{*}$ \\
II & 3 & 246 & 281 & 0,506000 \\
III & 4 & 117 & 130 & 0,598669 \\
IV & 0 & 6 & 17 & $1,7 \mathrm{E}-06^{*}$ \\
\hline Total & 16 & 445 & 568 & 0,224666 \\
\hline
\end{tabular}

da pluviosidade $\left(r^{2}=0,92\right)$. Os maiores valores ocorreram em novembro e fevereiro no primeiro período, e em dezembro e março no segundo (fig. 3).

Os valores do índice de atividade reprodutiva (IAR) foram de 6,7; 9,3; 7 e 7,4 nos trechos I, II, III e IV, respectivamente. Apesar do índice obtido no trecho II ser maior que os demais, todos os valores ficaram abaixo de 10 , indicando que a intensidade da reprodução é moderada.

A distribuição da freqüência do tamanho dos ovócitos mostrou que existem ovócitos de várias classes de tamanho dentro de uma gônada, e que duas modas ocorreram em sete amostras analisadas e três modas nas oito restantes. Quando os diâmetros foram agrupados, foi visualizado que ovócitos de vários tamanhos intermediários ocorreram entre o menor e o maior valor, e que, após o lote de reserva, um grande número destes ocorreu na classe de $0,058 \mathrm{~mm}$ e também acima de 3,015 $\mathrm{mm}$, mostrando que o desenvolvimento ovocitário é sincrônico em grupo e a desova, parcelada (fig. 4).

A contagem de ovócitos maduros mostrou variação entre 464 e 850 ovócitos, com fecundidade absoluta média de $663,95 \pm 141,99$ ovócitos. A razão entre o número de ovócitos e o peso total (fecundidade relativa) esteve entre 3,2 e 7,5 ovócitos/g, com fecundidade relativa média de $4,9 \pm 1,24$ ovócitos/g. O diâmetro médio dos ovócitos maduros foi de 3,33 mm e o diâmetro máximo foi de $4,14 \mathrm{~mm}$.

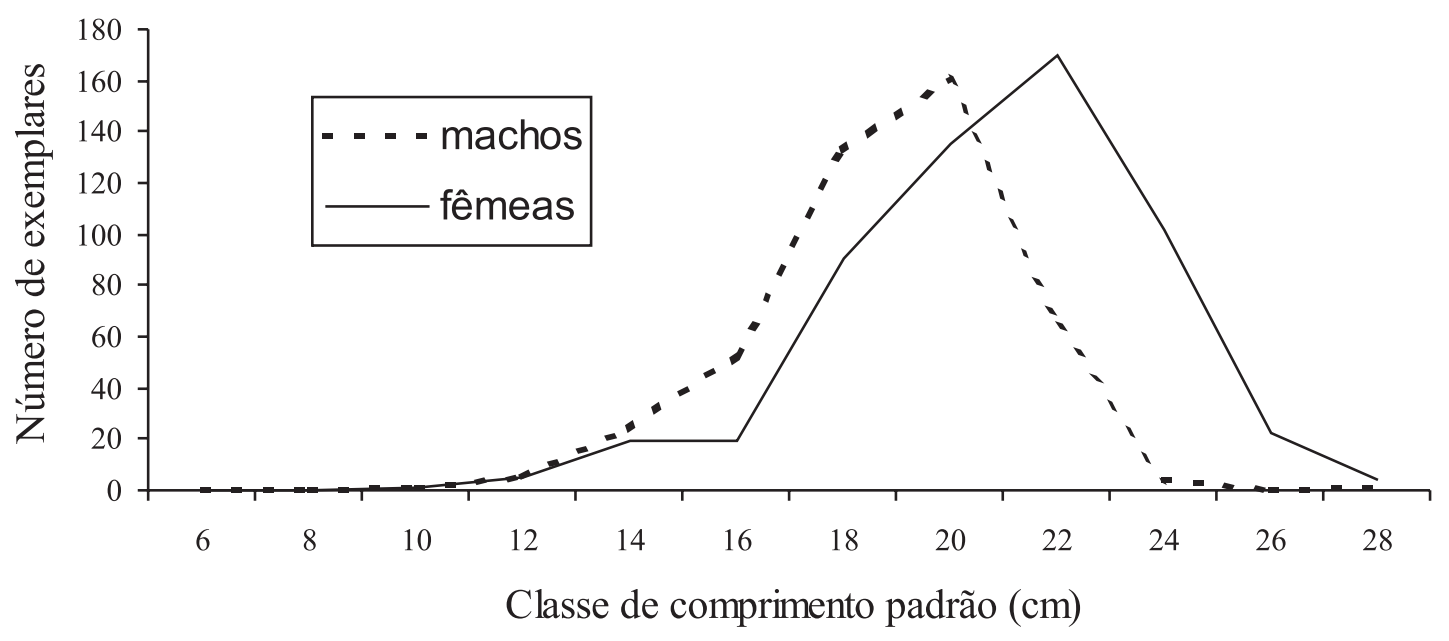

Fig. 2. Frequiência de indivíduos por classe de comprimento padrão de machos e fêmeas de Loricariichthys platymetopon coletados na represa Capivara entre abril de 2001 e março de 2003. 


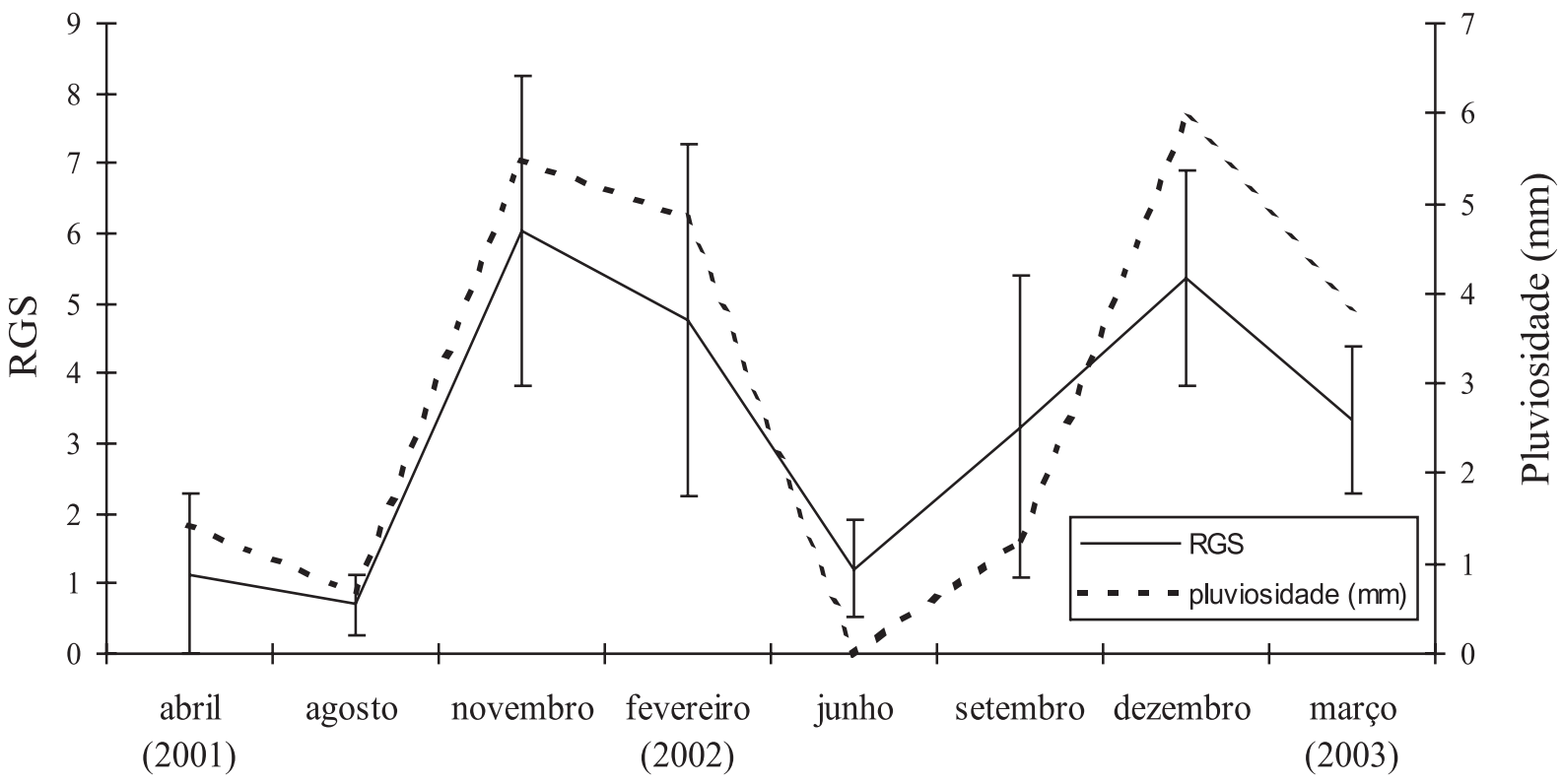

Fig. 3. Variação da relação gonadossomática média (RGS) e desvio padrão das fêmeas de Loricariichthys platymetopon em trechos influenciados pela represa Capivara.

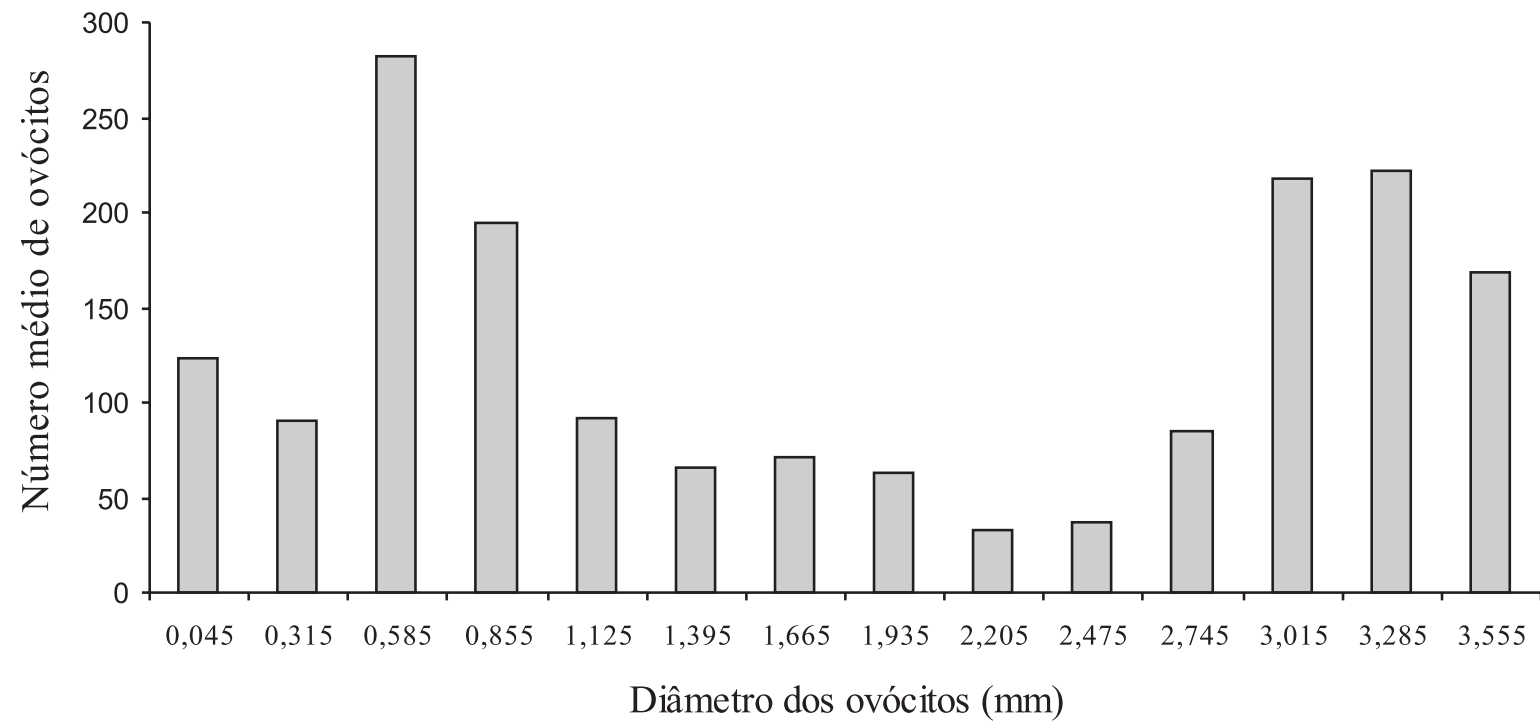

Fig. 4. Distribuição das médias das frequiências dos diâmetros dos ovócitos de 15 fêmeas de Loricariichthys platymetopon no estágio maduro, capturadas na represa Capivara.

\section{DISCUSSÃO}

L. platmetopon é atualmente uma das espécies mais abundantes na região de afluência do rio Tibagi com o rio Paranapanema, apesar de estudos anteriores não registrarem sua presença na região (BENNEMANN et al., 1995; 2000; Dias \& Garavello, 1998). Sua presença no alto rio Paraná está relacionada com a construção da barragem de Itaipu, que submergiu o Salto de Sete Quedas, o qual representava uma barreira natural à sua dispersão (Reis \& Pereira, 2000). Entretanto, essa mudança de condição de espécie rara para abundante, logo após o represamento, não pode ser comparada com a situação que ocorre na área influenciada pela represa Capivara, que existe há aproximadamente 30 anos.

A ictiofauna do rio Tibagi (inclusive o trecho correspondente ao III deste estudo) foi amostrada de 1992 a 1999 pela equipe do MZUEL, que não capturou a espécie nas primeiras coletas (BENNEMANn et al., 1995, 2000). ShibatTA et al. (2002) relatam sua presença em coletas posteriores (seu número de tombamento, MZUEL 1726, data de 1999). Neste caso, o aumento populacional provavelmente tem relação com sua recente presença 
nessa região e com condições favoráveis à sua reprodução e ao seu recrutamento.

Na região neotropical, a maioria das espécies de peixes que colonizam reservatórios procuram tributários ou áreas lóticas para a reprodução (Agostinho et al., 1999). A presença de grandes tributários ligados a um rio represado diminui os impactos negativos do represamento sobre a reprodução das espécies (Agostinho et al., 1994). Entretanto, a abundância de L. platymetopon foi maior no trecho II, um local lêntico, raso e sem tributários, o que sugere que a espécie não depende de afluentes para completar seu ciclo de vida.

Os números de exemplares capturados nos trechos I e III foram equivalentes. Esses locais recebem grandes afluentes e são mais profundos que o trecho II, discutido anteriormente, e são as áreas da represa Capivara onde o dourado, Salminus brasiliensis (Cuvier, 1816), está presente em maior número (DiAs \& GARAVELlo, 1998; ShibatTa et al., 2002). Salminus brasiliensis é um dos poucos predadores de L. platymetopon, espécie que compõe mais de $60 \%$ da sua dieta no rio Paraná (HAHN et al., 1997). Além disso, a velocidade da água pode dificultar o transporte de ovos pelos machos. A presença de lagoas marginais deve ter atenuado esse problema, pois a captura no trecho I não foi muito menor que no trecho III, que é semi-lótico. Agostinho \& Júlio JR. (1999) relatam que L. platymetopon é dominante em lagoas, não as deixando mesmo quando o oxigênio e a temperatura se tornam críticos devido ao baixo nível da água.

No trecho IV foi obtido o menor número de exemplares. Os poucos peixes obtidos eram adultos, e indivíduos jovens estiveram ausentes. Esse local é influenciado pela barragem e a estratificação térmica e a transparência são intensificadas pela profundidade, pela baixa velocidade da água e pelo longo tempo de residência da água (175 dias), sendo, portanto, um ambiente de sedimentação. $\mathrm{O}$ aumento da profundidade e a temperatura tendem a reduzir a abundância de Siluriformes (TEJERINAGARRo \& Rodríguez, 1998). A temperatura influi na distribuição espacial dos peixes e a estratificação térmica reduz o espaço disponível, pois o hipolímnio torna-se inóspito devido à anoxia e aos metabólitos de bactérias anaeróbicas (MATTHEWs, 1998). A ocupação da barragem por L. platymetopon pode ter sido dificultada pela grande transparência da água e profundidade do local.

Para todos os trechos de coleta, o fato de exemplares adultos terem sido capturados em maior número que os indivíduos jovens indica que os equipamentos usados (peneiras, puçás e redes de arrasto) não foram eficientes para a amostragem de indivíduos de pequeno porte. Além disso, os estágios jovens de muitos peixes vivem em ambientes diferentes daqueles em que vivem os adultos (Lowe-McCoNnELl, 1999).

Em relação à proporção sexual, VAZzoLER (1996) lembra que a proporção entre machos e fêmeas pode diferir de 1:1 devido a diferenças na taxa de crescimento, no comportamento ou na mortalidade. No caso de $L$. platymetopon, as fêmeas atingem maior tamanho que os machos, mas elas não foram mais capturadas que os machos em todos os trechos. A proporção sexual foi equilibrada nos trechos com os maiores números de exemplares capturados (II e III) e o maior número de fêmeas ocorreu nos trechos I e IV. A importância ecológica da proporção sexual ainda é incerta e esse aspecto é pouco discutido nos estudos sobre estrutura populacional. NiKOLSKY (1963) informa que a variação na proporção sexual pode ocorrer entre populações de uma mesma espécie e entre diferentes períodos dentro de uma mesma população, mas geralmente é uma adaptação que assegura a predominância de fêmeas quando as condições são muito favoráveis à produção de ovos, como durante a colonização de um novo ambiente ou quando a espécie sofre pesca intensiva. Como L. platymetopon não sofre captura comercial na represa Capivara, o maior número de fêmeas provavelmente se relaciona com a ocupação do ambiente.

A variação no tamanho corpóreo é um dimorfismo sexual de ocorrência generalizada entre os peixes, sendo que o predomínio de fêmeas nas maiores classes de tamanho foi relacionado por NiKOLSKY (1963), Gross \& SARGENT (1985) e LowE-McConNELL (1999) à seleção para o aumento da fecundidade. As fêmeas também atingem maior tamanho e peso em outros loricarídeos que carregam ovos, como em L. anus (Valenciennes, 1840) (BRUSCHI JR. et al., 1997) e, apesar da pequena amostra que TAYLOR (1983) obteve, nela as fêmeas eram maiores que os machos em L. platymetopon, L. labialis (Boulenger, 1895) e Loricaria simillima Regan, 1904.

NIKOLSKY (1963) relata que o macho tende a ser maior em espécies que defendem a prole no ninho contra outros peixes e predadores, o que não é o caso de $L$. platymetopon. Neste estudo, durante as coletas de campo, foi observado que os exemplares que carregavam ovos os abandonavam quando eram capturados. Provavelmente, o maior tamanho dos machos é uma vantagem para os loricarídeos que cuidam dos ovos em ninhos e que são territorialistas, como foi observado para Liposarcus anisitsi (Eigenmann \& Kennedy, 1903) (CRUZ \& LANGEANI, 2000), espécie na qual os maiores indivíduos vencem a competição pelas áreas mais adequadas e os machos visitantes são atacados desde a construção do ninho até a eclosão dos ovos. Para as espécies Rineloricaria uracantha (Kner, 1863) (Moodie \& Power, 1982) e Hypostomus commersonii Valenciennes, 1836 (AgostinHo et al., 1991) não há registro de comportamento agressivo, mas os maiores indivíduos de ambos os sexos se reproduzem primeiro que os de menor tamanho, devido à competição por ninhos.

A reprodução ocorreu entre novembro e fevereiro, nos meses de maior pluviosidade, embora uma determinação mais exata tenha sido impedida pelo fato de as coletas terem sido trimestrais. A amplitude do desvio padrão das médias de RGS em cada amostragem indica que indivíduos em diferentes fases de maturação ocorrem em um mesmo período e que alguns deles podem se reproduzir fora do período reprodutivo da maior parte da população. A variação do nível da água corresponde à da atividade reprodutiva, mas, aparentemente, não influencia a abundância.

Apesar da maior abundância de L. platymetopon no trecho II, os valores de IAR foram semelhantes em todos os trechos estudados, indicando que a intensidade reprodutiva é moderada. O caráter moderado da 
reprodução provavelmente é uma característica dessa população nesse local, já que um estudo no rio Paraná revelou que essa espécie é capaz de demonstrar valores de IAR superiores a 20 (Dei Tos et al., 1997), embora a periodicidade de amostragem possa subestimar o IAR (OrSI et al., 2002). Neste estudo, foram comparados o IAR da assembléia de peixes do trecho correspondente ao III em diferentes períodos e o menor valor foi obtido no ano em que as coletas foram mais espaçadas.

A grande abundância de L. platymetopon, o maior número de captura em ambientes distantes da barragem, o predomínio de fêmeas nas maiores classes de tamanho, a ocorrência da reprodução quando a temperatura é maior e a desova parcelada são dados semelhantes entre este estudo e os realizados no rio Paraná por Dei Tos et al. (1997) e SuzuKi et al. (2000). Porém, enquanto na represa Capivara a intensidade reprodutiva foi moderada e pouco variou entre os trechos, no alto rio Paraná (próximo à cidade de Porto Rico), ela variou entre os trechos, sendo mais intensa em ambientes lênticos do que em ambientes semi-lóticos e lóticos. Lá, as fêmeas predominaram a partir de $18 \mathrm{~cm}$ (Dei Tos et al., 1997), a fecundidade máxima e a relativa foram mais elevadas e o diâmetro médio do ovócito maduro foi menor (SUZuKi et al., 2000).

O cuidado parental envolve diferentes comportamentos, como a construção, a manutenção e a defesa do ninho, ventilar ovos com a boca ou nadadeiras para aumentar a oxigenação e dispensar sedimentos e metabólitos; limpeza e remoção dos ovos doentes ou mortos; carregamento dos ovos ou larvas na boca ou câmara branquial e ajuda na captura de comida (HERMAN et al., 2000). Nas espécies que apresentam algum tipo de cuidado parental, os ovos são maiores, levam mais tempo para eclodir e geram filhotes mais viáveis (BALON, 1975). Apesar de aumentar a sobrevivência da cria, este comportamento acarreta em alguns custos para o guardião, como o aumento da exposição a predadores, restrição do deslocamento e da alimentação e diminuição da fecundidade (Herman et al. 2000; Gross \& SARGENT, 1985). Neste caso, a desova parcelada é um mecanismo que aumenta o esforço reprodutivo e não somente o distribui ao longo do período reprodutivo (BURT et al., 1988). A desova de múltiplos lotes aumenta a fecundidade mais do que o permitido por uma desova total (BURT et al., 1988; VAZZOLER, 1996).

Entre os loricarídeos, as espécies que exercem algum tipo de cuidado parental protegem os ovos em ninhos ou cavidades, ou carrega-os na superfície corporal. O carregamento de ovos é uma estratégia reprodutiva eficiente em ambientes que apresentam variações nas condições limnológicas e no nível da água, sendo uma adaptação eficiente para superar a competição por cavidades adequadas para a construção de ninhos (Moodie \& Power, 1982). A baixa transparência inibe a localização pelos predadores e o carregamento reduz o impacto da turbidez e do baixo teor de oxigênio dissolvido (DeI Tos et al., 1997). Provavelmente, os ovos depositados em áreas marginais pelos guardadores sejam passíveis de exposição ao ar quando o nível da água baixa, situação que é comum em reservatórios. No caso da UHE Escola de Engenharia Mackenzie, a vazão defluente variou de 295 a $1.750 \mathrm{~m}^{3} / \mathrm{s}$ em 2001 e de 419 a
$5.348 \mathrm{~m}^{3} / \mathrm{s}$ em 2002, gerando variações marcantes no nível da água (no primeiro mês de coleta, por exemplo, a vazão máxima foi de $1430 \mathrm{~m}^{3} / \mathrm{s}$ e a mínima de $430 \mathrm{~m}^{3} / \mathrm{s}$ ).

Ainda não é possível saber se L. platymetopon se estabilizará como uma espécie dominante na região do médio rio Paranapanema e se irá se dispersar ao longo dos demais reservatórios e do rio Tibagi. O número de exemplares capturados variou de forma acentuada entre os trechos e amostragens, mas a abundância dessa espécie atesta sua capacidade de ocupação rápida do reservatório.

Agradecimentos. A Ângela T. Silva e Souza, Sirlei T. Bennemann e Harumi I. Suzuki, pelas sugestões; a Edson Santana, Aparecido Souza, Armando C. Casemiro e Fábio Bruschi, pelo auxílio nas coletas de campo. À Capes, Universidade Estadual de Londrina e Duke Energy International, pelo apoio financeiro Este estudo é parte do Projeto de Caracterização Biológica da Ictiofauna da UHE Escola de Engenharia Mackenzie (Capivara), cadastrado na UEL-PROPPG sob $n^{\circ} 17508 / 2000$. As coletas dos peixes foram autorizadas pelo IBAMA, licença DIREN 35/2000 de 3 de agosto de 2000

\section{REFERÊNCIASBIBLIOGRÁFICAS}

Agostinho, A. A. \& Júlio, H. F., JR. 1999. Peixes da bacia do alto rio Paraná. In: Lowe-McConnell, R. H. Estudos ecológicos de comunidades de peixes tropicais. São Paulo, Edusp. p. 374-400.

Agostinho, A. A.; Julio, H. F., Jr. \& Petrere, M., Jr. 1994. Itaipu reservoir (Brazil): Impacts of the impoundment on the fish fauna and fisheries. In: Cowx, I. G. ed. Rehabilitation of freshwater fisheries. Oxford, Fishig News Books, Blackell Science. p.171-184.

Agostinho, A. A.; Hahn, N. S. \& Agostinho, C. S. 1991. Ciclo reprodutivo e primeira maturação gonadal de fêmeas de Hypostomus commersonii (Valenciennes, 1840) (Siluriformes, Loricariidae) no reservatório Capivari-Cachoeira, PR. Revista Brasileira de Biologia 51(1):31-37.

Agostinho, A. A.; Mendes, V. P.; Suzuki, H. I. \& Canzi, C. 1993 Avaliação da atividade reprodutiva da comunidade de peixes dos primeiros quilômetros a jusante do reservatório de Itaipu. Unimar 15 (supl.): 175-189.

Agostinho, A. A.; Miranda, L. E.; Bini, L. M.; Gomes, L. C.; Thomaz, S. M. \& SuzUKI, H. I. 1999. Patterns of colonization in neotropical reservoirs, and prognoses on aging. In: TundisI, J. G. \& S Traskraba, M. eds. Theoretical reservoir ecology and its applications. São Carlos, International Institute of Ecology, Brazilian Academy of Sciences and Backhuys Publishers. p.227-265.

BALON, E. K. 1975. Reproductive guilds of fishes: a proposal and definition. Journal of Fisheries Research Board of Canada 32(6):821-864.

Bennemann, S. T.; Silva-Souza, A. T. \& Rocha, G. R. A. 1995. Composicion ictiofaunistica en cinco localidades de la cuenca del rio Tibagi, PR-Brasil. Interciencia 20:7-13.

Bennemann, S. T.; Shibatta, O. A. \& Garavello, J. C. 2000 Peixes do rio Tibagi: uma abordagem ecológica. Londrina, Eduel. 62p.

Bruschi, W., Jr.; Peret, A. C.; Verani, J. R. \& Fialho; C. B. 1997. Reprodução de Loricariichthys anus (Valenciennes, 1840) da Lagoa Emboaba, Osório, RS, Brasil. Revista Brasileira de Biologia 57(4):677-685.

Burt, A.; Krammer, D. L.; Nakatsuru, K. \& Spry, C. 1988. The tempo of reproduction in Hyphessobrycon pulchripinnis (Characidae) with a discussion on the biology of "multiple spawing' in fishes. Environmental Biology of Fishes 22(1): 15-27

Carvalho, E. D. \& Silva, V. F. B. 1999. Aspectos ecológicos da ictiofauna e da produção pesqueira do reservatório de Jurumirim (alto do rio Paranapanema, São Paulo). In: Henry, R. ed. Ecologia de reservatórios: estrutura, função e aspectos 
sociais. Botucatu, Fapesp. p.771-799.

Cruz, A. L. \& Langeani, F. 2000. Comportamento reprodutivo do cascudo Liposarcus anisitsi (Eigenmann \& Kennedy, 1903) (Ostariophysi: Loricariidae: Hypostominae) em cativeiro. Comunicações do Museu de Ciências e Tecnologia da PUCRS, Série Zoologia, 13:109-115.

Dei Tos, C.; Agostinho, A. A. \& Suzuki, H. I. 1997. Population structure and reproductive biology of Loricariichthys platymetopon (Siluriformes, Pisces) in the upper river Paraná. Brazilian Archives of Biology and Technology 40(4):793-807.

Dias, J. H. P. \& Garavello, J. C. 1998. Ecological studies on the fish community of Salto Grande reservoir, Paranapanema river basin, São Paulo, Brazil. Verhandlungen International Verein Limnology 26:2228-2231.

Duke Energy International Geração Paranapanema. 2003. Peixes do rio Paranapanema. São Paulo, Horizonte Geográfico. $112 \mathrm{p}$.

Gross, M. R. \& SARgent, R. C. 1985. The evolution of male and female parental care in fishes. American Zoologist 25:807-822.

Hahn, N. S.; Andrian, I. F., Fugi, R. \& Almeida, V. L. L. 1997. Ecologia trófica. In: Vazzoler, A. E. A. M.; Agostinho, A. A. \& Hahn, N. S. eds. A planície de inundação do alto rio Paraná: aspectos físicos, biológicos e socioeconômicos. Maringá, Eduem. p.209-228.

Herman, G. S.; Collete, B. B. \& Facey, D. E. 2000. The diversity of fishes. Massachusetts, Blackwell Science. 528p.

Lowe-McConnell, R. H. 1999. Estudos ecológicos de comunidades de peixes tropicais. São Paulo, Edusp. 535p.

Matthews, W. J. 1998. Patterns in freshwater fish ecology. New York, Chapman \& Hall. 756p.

Moodie, E. E. \& Power, M. 1982. The reproductive biology of an armoured catfish, Loricaria uracantha, from Central America. Environmental Biology of Fishes 7(2):143-148.
Nikolsky, G. V. 1963. The ecology of fishes. Nova York, Academic. $352 \mathrm{p}$.

Orsi, M. L.; Shibatta, O. A. \& Silva-Souza, A. T. 2002. Caracterização biológica de populações de peixes do rio Tibagi, localidade de Sertanópolis. In: Medri, M. E.; Bianchini, E.; Shibatta, O. A. \& Pimenta, J. A. A bacia do rio Tibagi. Londrina, M.E. Medri. p.425-432.

Querol, M. V. M.; Querol, E. \& Gomes, N. N. A. 2002. Fator de condição gonadal, índice hepatossomático e recrutamento como indicadores do período de reprodução de Loricariichthys platymetopon (Osteichthyes, Loricariidae), bacia do rio Uruguai médio, sul do Brasil. Iheringia, Série Zoologia, 92(3): $1-112$.

Reis, R. E. \& Pereira, E. H. L. 2000. Three new species of the loricariid catfish genus Loricariichthys (Teleostei: Siluriformes) from southern South America. Copeia 4:1029-1047.

Shibatta, O. A.; Orsi, M. L., Bennemann, S. T. \& Silva-Souza, Â. T. 2002. Diversidade e distribuição de peixes na bacia do rio Tibagi. In: Medri, M. E.; Bianchini, E.; Shibatta, O. A. \& Pimenta, J. A. A bacia do rio Tibagi. Londrina, M.E. Medri. p.403-423.

Suzuki, H. I.; Agostinho, A. A. \& Winnelmiller, K. O. 2000. Relationship between oocyte morphology and reproductive strategy in loricariid catfishes of the Paraná river, Brazil. Journal of Fish Biology 57:791-807.

TAYlOR, J. N. 1983. Field observations on the reproductive ecology of three species of armored catfishes (Loricariidae: Loricariinae) in Paraguay. Copeia 1:257-259.

Tejerina-Garro, F. L. \& Rodríguez, M. A. 1998. Fish community structure in relation to environmental variation in floodplain lakes of the Araguaia river, Amazon basin. Environmental Biology of Fishes 51:399-410.

VAZzoler, A. E. A. M. 1996. Biologia da reprodução de peixes teleósteos: teoria e prática. Maringá, Eduem. 169 p.

Recebido em dezembro de 2004. Aceito em maio de 2005. ISSN 0073-4721

Artigo disponível em: www.scielo.br/isz 